\title{
De artistas, consumidores y críticos: dinámicas del cambio, el gusto y la distinción en el campo artístico actual. Jean-Luc Godard y su Adiós al Lengu
}

\section{Levis Bilsky, Lucía}

Resumen: en este artículo nos

proponemos partir de la última obra de Jean-Luc Godard, Adiós al lenguaje, en tanto objeto cultural de nuestra sociedad actual, para introducirnos en los debates teóricos en torno a las lógicas de producción, distinción y cambio del campo artístico contemporáneo. Tomaremos principalmente los aportes teóricos de Pierre Bourdieu, su conceptualización sobre el campo de producción restringido, la idea de "eficacia mágica" de la obra de arte, las disquisiciones acerca del arte por el arte versus el arte medio, y la noción de "sociedades de admiración mutua", entre otros aportes. A su vez, mediante el análisis de varios artículos de opinión referidos a Adiós al

Cuadernos del Centro de Estudios de Diseño y Comunicación № 62

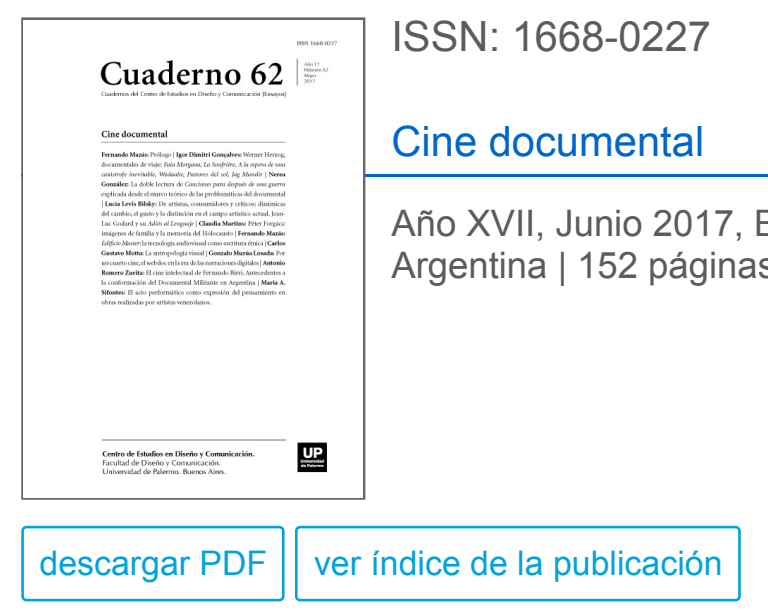

Ver todos los libros de la publicación

compartir en Facebook lenguaje, analizaremos el papel que juega la crítica en la elevación de esta obra, y las dinámicas del gusto, la distinción y el cambio propias del campo cultural, en lo que hace tanto al cine de ficción como al documental -extrapolable también a todas las otras producciones artísticas contemporáneas.

Palabras clave: Godard - campo de producción restringido - cine - crítica - arte contemporáneo.

$\left(^{*}\right)$ Graduada de la carrera de Ciencias Antropológicas de la UBA. Finalizando sus estudios en la Maestría de Cine Documental, en la Universidad del Cine.

"A estos cosos modernos tenés que apoyarlos aunque no te gusten, porque sino te dicen que sos un burro". (Atilio Mentasti, citado en Ámbito Financiero, edición electrónica, Adiós al lenguaje, hola al sopor) “...el gusto es el principio de todo lo que se tiene, personas y cosas, y de todo lo que se es para los otros, de aquello por lo que uno se clasifica y por lo que le clasifican" (Bourdieu, 1999, p. 53) Una película recientemente estrenada en el cine -en una pequeña cantidad de salas- ha despertado grandilocuentes y majestuosas críticas en las revistas 
experimentadas de cine, y unas pocas atrevidas notas que la describen con adjetivos ligados al campo semántico de la pedantería, del sopor, del aburrimiento y de lo incomprensible. Qué mejor que tomar el film en cuestión, la última incursión audiovisual de Jean-Luc Godard, Adiós al lenguaje, en tanto objeto cultural de nuestra sociedad actual, para introducirnos de lleno en los debates teóricos en torno a las lógicas de producción, distinción y cambio del campo artístico contemporáneo. Eficacia mágica de la obra de arte, arte por el arte versus arte medio, sociedades de admiración mutua, son algunos de los conceptos que utiliza Pierre Bourdieu, en su vasto abordaje del campo cultural. Más que útil resultarán sus conceptualizaciones para comprender la emergencia y la repercusión del último trabajo de Godard - cineasta, ensayista, experimentador por excelencia, símbolo y "profeta" de lo que tomando a Bourdieu podríamos llamar el "campo de producción restringido" en el mundo del arte contemporáneo, y en particular del cine.

Al hablar de la producción cultural de bienes simbólicos, Bourdieu explica que la misma obedece a dos lógicas diferentes, que se pueden pensar cada una correspondiendo a campos distintos: uno, el campo de la producción restringida, el otro, el campo de la gran producción. El primero de ellos produce bienes simbólicos para un reducido grupo social, especializado, experto, sujetos que también son ellos mismos productores de bienes simbólicos. El artista inserto en este campo restringido produce, en definitiva, para su grupo de pares, quienes sostienen con su reconocimiento la legitimidad del productor y del objeto creado, dentro de sus propias normas de producción y de evaluación. El segundo campo, en contraposición, produce bienes simbólicos destinados al gran público, a los no-productores, a los no-intelectuales. Este segundo campo, explica Bourdieu, el del "arte medio", “...obedece primordialmente a los imperativos de la concurrencia por la conquista del mercado..." (Bourdieu, 2003, p. 114), se orienta a la búsqueda de un efecto, de lograr la mayor cantidad de público -público "medio", que comanda las elecciones estéticas y técnicas del productor. Esta dicotomía entre aquello que apunta a un erudito círculo de entendedores, a una priviliegiada élite intelectual-artística, y aquello otro dirigido al mercado, a las "masas", se reproduce en las distintas esferas de la producción cultural, como bien explica Bourdieu. La dicotomía entre comercial/no comercial; arte tradicional/arte de vanguardia; arte burgués/arte intelectual, se reproduce en sus distintas manifestaciones.

El cine, claramente, no es la excepción. Y Godard, definitivamente, está ubicado en polo que apunta a los sabios entendedores, quienes otorgan su halo sagrado, su creencia y su sostén legitimante a esta obra complejísima en su (in)inteligibilidad.

Adiós al lenguaje podríamos pensarla como collage, como ensayo audiovisual, plagada de intertextualidades y citas de autores diversos, en la cual la experimentación formal adquiere protagonismo, por sobre cualquier intento narrativo convencional. Es de entender que si uno se acerca desde lo meros sentidos, encuentre displacer auditivo y visual, y carencia de una linealidad narrativa que haga posible encontrar en la obra ningún tipo de estructura clásica de relato. A su vez, si de algo no se despide en lo absoluto es del lenguaje, en ninguna de sus formas: desde lo verbal, la apelación al pensamiento de diversos filósofos abunda, como así también los diálogos enrevesados, las frases herméticas; la búsqueda de un lenguaje alternativo, desde lo visual y lo sonoro, también entra en su esplendor, apelando a la estética del "error", a encuadres incómodos, al ruido, a un uso desarticulado del 3D. Así, claramente, no es una obra de fácil aproximación, ni que apunte a un público amplio, acostumbrado a otro tipo de experiencia sensorial y simbólica, en lo que al cine refiere. Así, Adiós al lenguaje (en verdad, gran parte de las obras godardianas) responden al carácter "puro" y "esotérico" que Bourdieu atribuye a las obras de arte producidas en el campo de producción restringida, las cuales exigen una "disposición propiamente estética", "[cuya] estructura compleja [...] implica siempre la referencia tácita a toda la 
historia de las estructuras anteriores..." (Bourdieu, 2003, p. 101). Así, para entenderla, para descifrarla, es necesario contar con códigos apropiados, no distribuidos igualitariamente entre el universo entero de los posibles receptores.

Mientras que la recepción de los productos del sistema de gran producción simbólica es casi independiente del nivel de instrucción de los receptores (lo que se comprende, ya que este sistema tiende a ajustarse a la demanda), las obras de arte erudito deben su rareza propiamente cultural, y por ello, su función de distinción social, a la rareza de los instrumentos de su desciframiento, es decir, a la desigual distribución de las condiciones de la adquisición de la disposición propiamente estética que ellas exigen y del código necesario para su desciframiento [...] (Bourdieu, 2003, p. 102) Aquí, precisamente, otro elemento importante entra en juego, no mencionado hasta ahora: la rareza cultural y su función de distinción social. En su obra La distinción, Pierre Bourdieu trae a colación las reflexiones de Ortega y Gasset sobre el efecto que el "arte nuevo" produce, al dividir al público en "dos castas antagónicas, los que lo entienden y los que no lo entienden". "El arte nuevo, por lo visto, no es para todo el mundo, como el romántico, sino que va, desde luego, dirigido a una minoría especialmente dotada", no a la "masa incapaz de sacramentos artísticos", siendo que así el arte joven "contribuye a que los 'mejores' se conozcan y reconozcan en el gris de la muchedumbre y aprendan su misión, que consiste en ser pocos y tener que combatir contra la multitud" (Extractos de Ortega y Gasset, citados en Bourdieu,1999, p. 29). Justamente, es esta función de "distinción social" que pareciera seguir rigiendo hoy día, y que permite entender la producción y circulación de bienes simbólicos, y las distintas lógicas que hacen a las elecciones, el gusto y "la disposición artística" de los endógamos circuitos del arte erudito, de productores para productores, de especialistas que crean sus propios criterios de validación y legitimidad, y por otro lado "la estética popular", la de las grandes masas, la del arte mercantil.

Uno de los elementos de esta diferencia entre ambos campos, en la práctica, está ligado al tipo de búsqueda estética, de la relación entre forma y contenido, o a la relación de continuidad o discontinuidad entre el arte y la vida, según explica Bourdieu. En la "estética popular" la forma se encuentra subordinada a la función, asociada a la puesta en práctica de unas subyacentes normas del placer y de la moral, a la imagen significante, provista de sentido, de referente, a la continuidad entre el arte y la vida. El tema por sobre la forma.

En contraposición, la "estética culta"del campo de producción restringido estaría marcada por la investigación formal (que vuelve incomprensible la obra para los "no iniciados", para el público general), por la primacía de la forma por sobre el contenido, la experimentación estética por sobre la búsqueda de la "belleza" ordinaria del mundo. Con la experimentación formal, tan propia de la obra de Jean Luc Godard, los ojos no preparados se inquietan. A este respecto Bourdieu afirma: Si lasinvestigaciones formales [...] desconciertan es, por una parte, porque uno se siente incapaz de comprender lo que, en calidad de signos deben significar. [...] Al no conocer cuál es la intención de aquellas, no se siente uno capaz de discernir lo que es resultado de la audacia y lo que es de la torpeza, de distinguir la investigación "sincera" de al cínica impostura.

(Bourdieu, 1999, p. 40) En Adiós al lenguaje, los encuadres "desprolijos", las irregularidades de sonido, la hipersaturación de los colores, la discontinuidad narrativa, son elementos corrientes, complicados de codificar para espectadores no expertos, que busquen linealidad y estructura.

Marcas de distinción, de pertenencia, de conversación con y producción para su círculo de pares, para sus eruditos admiradores y sostenedores, celebrantes y creyentes, para su "grupo mágico" sin el cual se 
desvanecería el "poder del mago", la eficacia casi mágica de su firma (Bourdieu, 2003, p. 164). Godard, celebrado por su círculo de pares, encarna el lugar del "mago" creador sostenido por la creencia colectiva, legitimante de su obra.

...la producción de la obra de arte como objeto sagrado y consagrado [es] producto de una inmensa empresa de alquimia social en al cual colaboran, con la misma convicción y con beneficios muy desiguales, el conjunto de los agentes comprometidos en el campo de producción, es decir, los artistas y los escritores [...], los críticos y los editores tanto como los autores, los clientes entusiastas no menos que los vendedores convencidos. (Bourdieu, 2003, p. 165) Adiós al lenguaje puede entenderse de esta manera, pues, como objeto sagrado y consagrado, resultante de cierta alquimia social.

Ahora bien, en este juego alquímico, ¿de qué manera entender el papel de la crítica? Según Bourdieu, se suele observar un fenómeno de solidaridad entre el artista y el crítico, siendo los mismos críticos miembros del campo de producción restringida, y contribuyendo a la autonomía y cerrazón del mismo, a su reproducción, proporcionando “una interpretación 'creadora' para el uso de los 'creadores' [...] formándose así 'sociedades de admiración mutua"' (Bourdieu, 2003, p. 92). Estos críticos, alabadores de las obras del selecto circuito de productores, ayudan a: Poner fuera de juego al público de los no-productores, [...] atestiguando, por sus interpretaciones de experto o sus lecturas 'inspiradas', la inteligibilidad de obras que están destinadas, por las condiciones mismas de su producción, a permanecer largo tiempo inaccesibles a todos los que no están lo suficientemente iniciados en los secretos de producción como para otorgarles al menos una presunción de inteligibilidad. (Bourdieu, 2003, p. 92) Así, las dinámicas de distinción por la producción de este tipo de bienes simbólicos (y por su consumo), están avaladas por -y van de la mano de- la creación de críticas sostenedoras de la obra en cuestión, volviendo así el proceso de producción y valoración "una relación de reconocimiento recíproco entre pares" (Bourdieu, 2003, p. 93), en su perfecta retroalimentación endogámica intelectual.

Yendo al caso de Adiós al lenguaje, vemos un sin fin de críticas positivas, herméticas, que hablan claramente desde dentro de un campo restringido, de una cultura de pocos para pocos, dirigiéndose al selecto público que puede sentirse interpelado por sus apreciaciones, a las vanguardias artísticas, a los sectores intelectuales, al grupo de pares, a los expertos.

Página/12, por ejemplo, diario destinado a las clases medias intelectuales de "izquierda", consumidoras y productoras de "arte culto" de vanguardia, digamos, en la crítica que presenta de la última película de Godard la describe como una "obra maestra", una "escultura audiovisual", de una "fulgurante y oscura poesía", como "un maravilloso objeto conceptual, muchas veces críptico pero también deslumbrante en sus revelaciones"1. En CineramaPlus, un sitio web especializado en "cine-arte", comienza su "inspirada crítica" (volviendo a la apropiada denominación de Bourdieu) con unas notas aclaratorias, ya marcando la frontera entre el público distinguido, merecedor de ir al encuentro de este film, y aquel que no, que no es digno de él, que no es "apto" para abordarlo -es decir, la frontera entre el adentro y el afuera del campo restringido, podríamos decir, volviendo a los planteos iniciales: ...el 10 [calificación dada por el crítico en cuestión] no habla de perfecciones, habla de lo imprescindible que es "Adiós al lenguaje" para quien está interesado en pensar desde el cine, para pensar la historia y el presente del cine, para pensar el arte. Para asumir el abismo de la incertidumbre que provoca cualquier verdadera obra de arte. 
Luego continúa con otra nota aclaratoria: Nota III: quien pretende una película narrativa, que le resulte fácil de "entender" y en la cual pasen cosas tales como presentación, nudo, desarrollo y desenlace, puede evitar "Adiós al lenguaje". Como debería hacerlo con la gran parte de la obra de Picasso, con "La hija de la lágrima" de Charly García o con la maravillosa prosa de Clarice Lispector2.

Ahora bien, en el diario Clarín, cuyo público es de "amplio espectro", diríamos, sectores medios en general, ya el crítico incluye en sus comentarios aclaraciones respecto a lo tediosa, ininteligible y frustrante que puede resultar -pensemos en el lector "medio" no intelectual al que apunta esta nota.

Adiós al lenguaje es un desafío a la paciencia, un recordatorio de que ante toda expresión artística, lo mejor que puede hacerse es relajarse y gozar. O relajarse y sufrir, pero siempre dejarse llevar y nunca intentar buscarle el sentido, la explicación, a lo que se está viendo, porque por ese camino se marcha directo a la frustración.

Más adelante continúa: "Este bombardeo de frases de autoridad es lo que vuelve todo un tanto pretencioso, abrumador y, por momentos, desconcertante"; "en su faceta intelectual la película puede llegar a minar la autoestima de cualquier espectador". Y finalmente concluye, "La belleza de algunas imágenes, realzadas por el 3D, compensa cierta pretenciosidad y pedantería"3. Aquí vemos, nuevamente, cómo lo valorable, dentro de la "estética popular" está ligado, como bien explica Bourdieu, a la "belleza" común, al placer de los sentidos. Es eso lo que finalmente rescata el crítico en cuestión, al hablarle a su público medio.

Siguiendo con este recorrido por las críticas y sus públicos, resulta interesante traer a colación la que produjo el diario Ámbito Financiero -dirigido, ya deducible de su título, no precisamente a un público intelectual-en el cual el crítico directamente hace explícito aquello sobre lo cual Bourdieu teoriza ampliamente, y que con la frase citada al comienzo del artículo -y del presente trabajo- podemos resumir: "A estos cosos modernos tenés que apoyarlos aunque no te gusten, porque sino te dicen que sos un burro". En esta frase parecieran condensarse las dinámicas contrapuestas de un mercado artístico restringido (vanguardista, y elitista, el que produce "estos cosos modernos", para traer esa chistosa frase), y otro ampliado (el del público medio, el de los "burros" muchas comillas, por supuesto), las diferentes lógicas estéticas que subyacen a ellos, la cuestión de la rareza cultural (de la producción de ella, y del gusto por ella) como elemento de distinción social, de elevación, de pertenencia a determinado sector. El título de la crítica es muy clara respecto a la apreciación que Ámbito Financiero realiza de la obra "Adiós al lenguaje, hola al sopor".

Pareciera, este autor, ser el interlocutor del crítico que desde Cinema Plus descalificaba a aquellos no "aptos" para acercarse a esta obra de arte, cuando en sus notas aclaratorias expulsaba de sus "dignos" interlocutores a aquellos que buscaban una película narrativa, fácil de entender.

Ahora bien, qué se percibe en estas críticas? Pareciera tratarse de reflejos de las dos lógicas una y otra vez citadas, y de la reproducción de las mismas: por un lado, inspirados y eruditos análisis que dan cuenta de las marcas de "superioridad" intelectual y artística de algunos sectores dominantes, de la endogamia artística y la profunda solidaridad entre el artista y el crítico, el "halo mágico" producido por la creencia colectiva -legitimante, sostenedora del acto "mágico", de la obra. Por otro lado, el afuera, el mero Otro, "no hecho para" este tipo de gustos, este tipo de obras, este tipo de distinción. 
La constante búsqueda de ruptura de Godard, de experimentación formal, tan común en todas sus obras, y presente intensamente en esta última, es entendida como "burla" al espectador por el crítico del diario Ámbito Financiero, "vocero" en algún sentido de ese mero "Otro" externo al campo restringido: El film cuestiona al espectador, y éste se cuestiona lo que está viendo, y se pregunta cosas como ¿ese efecto es buscado o medio se tildó? ¿es un problema del proyector? ¿será la copia? ¿serán los anteojitos? [...] Y aún caben más preguntas: ¿qué pasaría si se juntan un director con síndrome de Tourette y un camarógrafo con mal de Parkinson?4.

Podríamos pensar este tipo de ruptura constante de los códigos previamente establecidos, ese juego con el "error", esta innovación estética, la experimentación estilística, como aquel tipo de ruptura que Bourdieu describe como típica del campo de producción restringido, en tanto va progresando ...por rupturas casi acumulativas con los modos de expresión anteriores, [...] [aniquilando así] continuamente las condiciones de su recepción al exterior del campo: en la medida en que sus productos exigen instrumentos de apropiación de los cuales los mejor provistos entre los consumidores virtuales están al menos provisoriamente desprovistos, están destinados, por una necesidad estructural, a preceder su mercado, y por ello, están predispuestos a cumplir una función social de distinción... (Bourdieu, 2003, p. 100) El cambio, así, se vuelve inherente al devenir de todo campo -y por supuesto, también al campo artístico, y en particular al restringido- y así también contribuye a reproducir la creación de la diferencia, de la rareza, se vuelve un reproductor de la distinción, de los límites entre el adentro y el afuera, entre el Nosotros y los Otros, en ese selecto campo restringido.

Así, en verdad, el cambio no es drástico. Se trata de una continuidad del cambio, de una dialéctica entre continuidad y ruptura: lo constante es, precisamente, el cambio.

Bourdieu ya se ha manifestado claramente sobre este asunto, afirmando cómo el campo artístico es “... sede de revoluciones parciales que transforman su estructura sin poner en tela de juicio al campo como tal..." (Bourdieu, 1990, p. 186). Y ese cambio permanente debe entenderse en términos relacionales: los productores crean sus obras en función del lugar que ocupan en el espacio de producción, de las relaciones de fuerza que lo constituyen. En este sentido, este proceso inevitable de cambio, y la posibilidad de que el campo artístico "tome vuelo" por encima del gusto de los consumidores, debe entenderse considerando la posición social del productor en el espacio de producción -y la posición social de los consumidores. Tal como sostiene Pierre Bourdieu, "La divulgación devalúa; los bienes desclasados ya no confieren 'clase' [...] La rareza del producto y la rareza del consumidor disminuyen en forma paralela" (Bourdieu, 1990, p. 189). Siguiendo esta línea, el hecho de producir una obra artística innovadora, que rompa y se despegue de los consumidores (o más bien, del público masivo) sería una búsqueda por “...reintroducir la rareza...” (Bourdieu, 1990, p. 189), por alejarse de lo común, por distinguirse y elevarse sobre lo establecido, lo ordinario. El reconocimiento, en este tipo de dinámica de diferenciación y "elevación", no se busca en un público masivo, sino en el selecto grupo de pares -productores y consumidores conocedores, de círculos eruditos, esotéricos, de los que venimos hablando desde el comienzo. Así, ese "tomar vuelo" no es una separación respecto al gusto de todos los consumidores, sino más puntualmente del gusto masivo -siendo, así, una estrategia de distinción, de superación. Nuevamente, cómo no entender en esta clave la producción de Adiós al lenguaje, y así también las críticas y la enorme valoración asignada por los selectos círculos de artistas y conocedores.

Por supuesto, este tipo de dinámicas en el campo el arte pueden identificarse en todas las disciplinas, que mediante la introducción de la "extrañeza" y de lo masivamente poco atractivo -depositario de gran admiración para un selecto grupo de pares- van reproduciendo la exclusiva posición de los productores culturales en la 
jerarquía social. Basta asomarse a las exclusivas galerías de arte contemporáneo, con sus instalaciones, su arte conceptual, sus performances, para comprender estas estrategias de "vuelo" sobre los gustos culturales masivos.

Infinitos ejemplos podrían ser citados. En el mundo del cine, las vanguardias experimentales muestran claramente esto, con el paso de la "imagen-movimiento" a la "imagentiempo" (en términos deleuzianos), en filmes en los cuales se exacerba el sentir del tiempo, y en los cuales ninguna acción transcurre; el auge de los autorretratos, las videoinstalaciones, las videoperformances, los filmes consumidos únicamente en festivales, eruditos ciclos de cine, exclusivas escuelas de arte, y museos de arte contemporáneo. Hablando desde el interior de una carrera de posgrado en cine documental, los autores que son grandes eminencias en estas aulas, cotidianamente mencionados, resultan extrañamente conocidos por fuera de este círculo de pertenencia, por el público general. Harun Farocki, Stan Brakhage, Chris Marker, Yasujiro Ozu, Frederick Wiseman, y por supuesto, también nuestro ya tan citado Jean-Luc Godard, entre tantos otros. Mismo ejercicio se podría hacer en sucesivos párrafos, en cualquiera de las otras ramas del arte. La música contemporánea atonal, el teatro y la danza contemporánea experimental -que a mí, en tanto observadora/ consumidora exotérica me ha hecho dormir plácidamente en la butaca durante dos horas, durante las cuales cuatro artistas caminaron, simplemente caminaron, en cámara lenta por el escenario, con un patrón repetitivo de música perturbadora de fondo. Misma situación podría encontrarse en las artes performáticas, las obras de arte conceptual, y así sucesivamente. La cultura, como arena de disputas simbólicas, en una sociedad jerarquizada como la nuestra, pareciera dar lugar a diversas manifestaciones artísticas que dejan ver cómo el motor de cambio podría pensarse, en parte, como una estrategia de diferenciación, y de reproducción del hermetismo, de lo selecto, de lo exclusivo del "buen gusto" que representan los sectores de élite cultural.

Ahora bien, este tipo de cambio que acontece al interior del campo cultural podría también entenderse a partir del "impulso trascendente" fundamental de todo proceso intelectual, en términos de Karl Mannheim (1963), para quien la actitud intelectual que da lugar a la creación puede concebirse como resultante de un impulso, de una agitación, que partiendo del reconocimiento de la propia herencia cultural de (o lo que Raymond Williams conceptualizaría como "tradición") se ve propulsada a trascenderla -observable típicamente en la actitud del adolescente, desde la postura de Mannheim. Así lo expresa: La disociación con respecto a la propia situación previa y la búsqueda de un horizonte más amplio desde el contorno inicial son los impulsos principales [...]. El adolescente descubre las interpretaciones alternativas y los nuevos valores con un sentimiento de liberación. La afirmación de sí mismo y una actitud desafiante acompañan a esta experiencia. (Mannheim, 1963, p. 232) Por supuesto, el ejercicio mental que debemos hacer al utilizar el proceso intelectual del adolescente para pensar el acto creativo y el cambio al interior de cualquier campo -y en este caso en el artístico- exige considerar una serie de cuestiones. Primero, debemos reconocer que todo individuo creador está condicionado socialmente, como bien lo explica Raymond Williams, al trabajar sobre el concepto de "autor". Su individualidad está inmersa en las formas sociales de su contexto. En este sentido, el "impulso trascendente" que mencionaba Mannheim de todo proceso de cambio no estaría encarnado por un sujeto individual, sino por un sujeto social, o en otras palabras "transindividual" (tomando el concepto de Williams, 1977, p. 224): “...incluso mientras se procuran realizar proyectos individuales, lo que se está delineando es lo transindividual" (Williams, 1977, p. 224). Así, se debe comprender lo "...socialmente constitutivo, que nos permite observar una específica profesión de autor..." (Williams, 1977, p. 227), tanto en lo que tiene de reproductivo de un cierto orden, de una cierta tradición, como en lo que tiene de innovador (relacionado con los elementos "emergentes" que crecen en el seno de una 
tradición). Toda tradición, en tanto conjunto de significados y prácticas culturales seleccionadas, aceptadas, integradas, dominantes, debe entenderse en su dinámica relación que entabla en el proceso histórico cultural más amplio con los elementos residuales y con los emergentes (entendiéndose por esto último “...los nuevos significados y valores, las nuevas prácticas [...] que se crean continuamente” (Williams, 1977, p. 145). Así, una tradición particular no puede entenderse aisladamente, sino que siempre tiene que analizarse buscando observar las complejas relaciones que se van delineando a su interior y más allá de ella: las tendencias, los movimientos emergentes, los "impulsos trascendentes", los intereses de clase y distinción social (volviendo a lo que al comienzo desarrollamos): en fin, los elementos que van permitiendo el devenir del cambio, la dialéctica entre lo sincrónico y lo diacrónico5, o por qué no también, el "vuelo" del campo cultural, y la aparición de obras que algunos confundan con sucesión de errores, soporíferos productos ininteligibles, reestablecedores de los límites que el campo se esfuerza por mantener y recrear, entre un "Nosotros" conformado por selectos espectadores, y unos "Otros", masivos consumidores.

El arte por el arte, digo yo, el verso por el verso, el estilo por el estilo, la forma por la forma, la fantasía por la fantasía, todas estas enfermedades que corroen a nuestra época, como una enfermedad vergonzosa, es el vicio en todo su refinamiento, el mal en su quintaescencia. (Proudhon, 1939; citado en Bourdieu, 1999, p. 46) Notas 1. "Cuando el cine se vuelve escultura audiovisual", Página/12, 18 de diciembre de 2014. Disponible en: http://www.pagina12.com.ar/diario/suplementos/espectaculos/5-34285-2014-12-18.html 2. "Godard, un impresionista del siglo XXI", CineramaPlus, diciembre de 2014. Disponible en: http://cineramaplus.com.ar/? $p=6805$ 3. "Adiós al Lenguaje: experiemntal y sensitiva", Clarín, 17 de diciembre de 2014. Disponible en: http://www.clarin.com/extrashow/cine/Jean-Luc_Godard-Adios_al_lenguajecritica_0_1268273635.html 4. “Adios al lenguaje, hola al sopor", Ámbito Financiero, 18 de diciembre de 2014. Disponible en: http://www.ambito.com/diario/noticia_ee.asp?id=771754 5. O entre estructura e historia, sistema y acontecimiento, pasado y presente, retomando a Marshall Sahlins en sus reflexiones sobre la relación entre reproducción y cambio. (Sahlins, 1997, p. 144) Bibliografía consultada Bourdieu, P. (1990). Sociología y cultura. México: Grijalbo.

Bourdieu, P. (1999) La distinción. Criterio y bases sociales del gusto. Madrid: Taurus.

Bourdieu, P. (2003). Creencia artística y bienes simbólicos: elementos para una sociología de la cultura. Buenos Aires: Aurelia Rivera.

Mannheim, K., Manheim, E., Kecskemeti, P., Zaragüeta, J., \& Suárez, M. (1963). Ensayos de sociología de la cultura. Madrid: Aguilar.

Sahlins, M. (1997). Islas de historias. La muerte del capitán Cook. Metáfora, antropología e historia [1985]. Barcelona: Gedisa.

Williams, R. (1977). Marxismo y literatura. Barcelona: Península.

\section{Artículos periodísticos}

"Adiós al Lenguaje: experimental y sensitiva", Clarín, 17 de diciembre de 2014. Disponible en: http://www.clarin.com/extrashow/cine/Jean-Luc_Godard-Adios_al_lenguaje-critica_0_1268273635.html “Adios al 
lenguaje, hola al sopor", Ámbito Financiero, 18 de diciembre de 2014. Disponible en:

http://www.ambito.com/diario/noticia_ee.asp?id=771754 "Adios al lenguaje", Leedor, 16 de diciembre de 2014. Disponible en: http://www.leedor.com/contenidos/cine/adios-al-lenguaje "Adios al lenguaje", Hacerse la crítica, diciembre de 2014. Disponible en: http://www.hacerselacritica.com/adios-al-lenguaje-por-luciano-alonso/ "Cuando el cine se vuelve escultura audiovisual", Página/12, 18 de diciembre de 2014. Disponible en: http://www.pagina12.com.ar/diario/suplementos/espectaculos/5-34285-2014-12-18.html "Godard, un impresionista del siglo XXI", Cinerama Plus, diciembre de 2014. Disponible en: http://cineramaplus.com.ar/? p=6805 "La despedida", Leer Cine, diciembre de 2014. Disponible en: http://www.leercine.com.ar/nota.asp? id=494 Abstract: The article proposes a starting from the last work of Jean-Luc Godard, Goodbye to language, to go through the theoretical debates about logics in production, distinction and change of contemporary art field. The paper takes the theoretical contributions of Pierre Bourdieu, his concept about the restricted production field, the concept of "magical eficiency" applied to art work, the debates about art in itself and art as media and the concept of "societies of mutual admiration". In addition, we analyze the impact of critics in the raising of Goodbye to language, and the dynamics of taste, distinction and change referring to science-fiction cinema, documentary cinema and other contemporary art productions.

Key words: Godard - restricted production field - cinema - critics - contemporary art.

Resumo: Neste artigo nos ofertamos partir da última obra de Jean-Luc Godard, Adeus à linguagem, em tanto objeto cultural de nossa sociedade atual, para nos introduzir nos debates teóricos ao redor às lógicas de produção, distinção e mudança do campo artístico contemporâneo. Tomaremos principalmente os aportes teóricos de Pierre Bourdieu, sua conceitualizacão sobre o campo de produção restringido, a idéia de "eficácia mágica" da obra de arte, as disquisições sobre a arte pela arte versus a arte meia, e a noção de "sociedades de admiração mutua" entre outros aportes. Além disso, através da análise de artigos de opinião referidos a Adeus à linguagem, se analisarão o papel da crítica na elevação desta obra, e as dinâmicas do gosto, a distinção e a mudança próprias do campo cultural, no que faz tanto ao cinema de ficção como ao documental, extrapolado também a todas as outras produções artísticas contemporâneas.

Palavras chave: Godard - campo de produção restringido - cinema - crítica - arte contemporânea.

De artistas, consumidores y críticos: dinámicas del cambio, el gusto y la distinción en el campo artístico actual. Jean-Luc Godard y su Adiós al Lengu fue publicado de la página 43 a página53 en Cuadernos del Centro de Estudios de Diseño y Comunicación Nº 62 